\title{
A Qualitative Morphological Comparison of Two Haemostatic Agents in a Porcine Liver Trauma Model
}

\author{
Kenneth E. Coenye $^{1^{*}}$, Claire Bourgain ${ }^{2}$, Claudia Keibl ${ }^{3}$, Sylvia Nürnberger ${ }^{3,4}$, \\ Martijn van Griensven ${ }^{3}$ \\ ${ }^{1}$ Departments for Surgery and Emergency Medicine, AZ Jan Portaels, Vilvoorde, Belgium \\ ${ }^{2}$ Department for Pathological Anatomy, Free University Brussels (VUB), Brussels, Belgium \\ ${ }^{3}$ Ludwig Boltzmann Institute for Experimental and Clinical Traumatology in the Research Centre of the AUVA, Vienna, Austria \\ ${ }^{4}$ Department of Traumatology, Medical University, Vienna, Austria \\ Email: *kcoenye@azjanportaels.be
}

Received June 1, 2013; revised July 2, 2013; accepted July 10, 2013

Copyright (C) 2013 Kenneth E. Coenye et al. This is an open access article distributed under the Creative Commons Attribution License, which permits unrestricted use, distribution, and reproduction in any medium, provided the original work is properly cited.

\begin{abstract}
Background: Many surgical haemostatic agents are available which aim to reduce morbidity and mortality of bleeding, as well as associated costs. We used qualitative techniques to compare the effectiveness of two topical gelatine-based haemostatic agents in a porcine liver trauma model. Methods: We compared the activity of Floseal ${ }^{\mathbb{B}}$ (with human or bovine thrombin), Surgiflo ${ }^{\circledR}$ and Surgiflo ${ }^{\circledR}$ plus $5000 \mathrm{IU}$ bovine thrombin per $10 \mathrm{~mL}$ of product ( $\mathrm{n}=6$ test sites/group). Different clinical scenarios were evaluated in two anaesthetised piglets; normal physiological conditions (normotension and normothermia), and a status of hypotension, hypothermia and haemodilution, requiring inotropic support. Laparotomy was performed, and five identical stab wounds were made on each liver lobe. Four of these wounds were randomly treated with one of the agents under investigation, while one wound was kept as an untreated control. Haemostasis was observed during and immediately following surgery. After euthanisation, wounds were examined (blinded for treatment) macroscopically, microscopically and using scanning electron microscopic evaluation. Results: Surgiflo ${ }^{\mathbb{B}}$ produced some degree of clotting in $1 / 3$ applications in both piglets. Co-treatment with thrombin resulted in a minor improvement in performance in the animal with normal physiological conditions (some degree of clotting in all wounds); no improvement was seen in the animal in a status of hypotension, hypothermia and haemodilution. Floseal ${ }^{\mathbb{B}}$ induced clotting in all wounds for both piglets. Microscopic and scanning electron microscope examination of the stab wounds demonstrated that Floseal ${ }^{\circledR}$ created a stable, dense agglomerate of gelatine and fibrin, which firmly adhered to the adjacent liver tissue. In wounds treated with Surgiflo ${ }^{\circledR}$ or Surgiflo ${ }^{\circledR}$ plus thrombin, the gelatine contained more air bubbles, resulting in less fibrin inclusion in the clot and weaker adhesion of the clot to the liver tissue. Conclusion: Floseal ${ }^{\mathbb{B}}$ created a dense and stable blood clot, even in a piglet with hypotension, hypothermia and haemodilution.
\end{abstract}

Keywords: Haemostasis; Coagulation; Thrombin; Fibrin; Gelatine; Sealant; Clot; Surgery; Trauma; Wound Healing

\section{Introduction}

Techniques for controlling haemostasis during surgery have evolved over recent decades, from application of local pressure with moist gauze, to electrocautery, sutures, staples and haemostatic patches. Many topical agents designed to help control haemostasis during surgery have been licensed in the past decade. Surgical haemostatic agents can be collagen-based, gelatine-based, cellulosebased, polysaccharide-based or fibrin-based, and can also be inorganic in nature [1].

When classic haemostasis fails and surgeons need to

*Corresponding author. transfuse critically ill patients, or administer platelets or plasma products, morbidity and mortality rates increase, as do the costs associated with the surgery [2,3]. The latest commercially available agents claim to have an immediate effect in areas where haemostasis control is difficult or dangerous, thus reducing morbidity, mortality and associated costs. Haemostasis has been achieved in even the most severe trauma situations by using gelatine-based flowable agents [4].

In this experiment we set out to determine the effecttiveness of two of these gelatine-based agents, with or without the addition of thrombin, by means of observational and morphological evaluation in a clinically rele- 
vant pig model. Both the agents functioned via two mechanisms: activation of the intrinsic coagulation pathway as a result of contact between blood and the gelatine surface; and tamponading of bleeding by the gelatine as it swells following contact with blood. The added thrombin also directly induces fibrin formation $[5,6]$.

\section{Methods}

We compared the activity of two variants of Floseal ${ }^{\circledR}$ (Baxter Biosurgery Inc., Deerfield, Illinois, USA), a cross-linked gelatine matrix with either human (2500 IU) or bovine (5000 IU) thrombin, with Surgiflo ${ }^{\circledR}$ (Johnson \&Johnson Inc., New Brunswick, New Jersey, USA), which contains only gelatine. To compare fibrin clot formation induced by the two products, in addition to using Surgiflo ${ }^{\circledR}$ according to the manufacturer's instructions, we also used it with $5000 \mathrm{IU}$ bovine thrombin per $10 \mathrm{~mL}$ of agent added, instead of the saline solution with which it is intended to be used. In order to get a better understanding of the structure of the two gelatine agents, Surgiflo $^{\circledR}$ and Floseal ${ }^{\circledR}$ particles were analysed morphologically using scanning electron microscopy (SEM) before application to the wounds.

\subsection{In Vivo Analysis of the Ability of Surgiflo ${ }^{\circledR}$ and Floseal ${ }^{\circledR}$ to Control Haemostasis}

The effect of Surgiflo ${ }^{\circledR}$ and Floseal ${ }^{\circledR}$ was evaluated in two piglets. The first piglet provided a model of normal physiological conditions (normotension and normothermia), while the second animal was in a status of hypotension, hypothermia and haemodilution, requiring inotropic support) (Table 1). In order to maintain mean arterial pressure (MAP) in the second piglet, $9000 \mathrm{~mL}$ of crystalloid and colloid fluids were infused over $180 \mathrm{~min}$ utes, compared with only $7000 \mathrm{~mL}$ of crystalloids in the first piglet.

All experiments were approved by the animal protocol review board of the City Government of Vienna. Both piglets were premedicated with an intramuscular injecttion of a mixture of $30 \mathrm{mg}$ xylazine, $25 \mathrm{mg}$ ketamine, $10 \mathrm{mg}$ tiletamine, $10 \mathrm{mg}$ zolazepam and $5 \mathrm{mg}$ butorphanol, and were then intubated. Jugular, carotid and urinary catheters were inserted and general anaesthesia was maintained with inhaled oxygen and isoflurane $(1.5 \%-2 \%)$ and intravenous sufentanil $(0.008 \mathrm{mg} / \mathrm{kg} / \mathrm{h})$ and alcuronium $(0.8 \mathrm{mg} / \mathrm{kg} / \mathrm{h})$. A laparotomy was performed in each piglet, then five identical stab wounds approximately $3 \mathrm{~cm}$ apart from each other, were inflicted consecutively in each of the three liver lobes by making a crosslike incision of $12 \mathrm{~mm}$ wide and $10 \mathrm{~mm}$ deep with a selfmade stab device consisting of four perpendicular number 10 surgical blades in the shape of a cross.
Table 1. Physiological conditions of the animals during the experiment.

\begin{tabular}{ccc}
\hline Parameter & $\begin{array}{c}\text { Piglet 1 } \\
\text { (Physiological } \\
\text { conditions) }\end{array}$ & $\begin{array}{c}\text { Piglet 2 } \\
\text { (Hypotension, } \\
\text { hypothermia and } \\
\text { haemodilution) }\end{array}$ \\
\hline Weight (kg) & 30.5 & 30.6 \\
Sex & male & male \\
Mean arterial pressure start \\
$\begin{array}{c}\text { (mmHg) } \\
\text { Mean arterial pressure end } \\
\text { (mmHg) }\end{array}$ & 90 & 75 \\
Heart rate start (bpm) & 75 & 65 \\
$\begin{array}{c}\text { Heart rate end (bpm) } \\
\text { Mean temperature }\left({ }^{\circ} \mathrm{C}\right)\end{array}$ & 80 & 95 \\
Total volume infused (mL) & 76.5 & 32.0 \\
$\quad$ Colloids & 7000 & 9000 \\
Inotropic drugs & No & Yes \\
Urine output (mL) & 1400 & Yes \\
\hline
\end{tabular}

Bpm: beats per minute, ${ }^{*} 3000 \mathrm{~mL}$ Voluven ${ }^{\circledR},{ }^{* *}$ diluted noradrenalin and pure L-adrenalin to maintain blood pressure.

Each of the four agents was randomised to one stab wound per lobe (Table 2). A fifth stab wound inflicted to each lobe was treated with $2 \times 2$ minutes of gentle compression without the application of a haemostatic agent, to serve as a control. $5 \mathrm{~mL}$ of agent was applied to each wound (corresponding to an entire syringe of Floseal ${ }^{\mathbb{B}}$ and half a syringe of Surgiflo ${ }^{\circledR}$ ). Photographs were taken of each step of the procedure. After agents were applied to the bleeding site, soft compression with moist gauze was applied for exactly 2 minutes. The gauze was then removed and an initial observation of haemostasis recorded. If bleeding was still present, pressure was reapplied for a further 2 minutes. Next, any excess product was removed by gently rinsing with $10 \mathrm{~mL}$ of saline solution. Again, observations of haemostasis were recorded.

After euthanising the piglets in deep anaesthesia, the liver lobes were resected and tissue specimens of $1 \times 1 \times$ $1 \mathrm{~cm}$ around each stab wound were excised. These blocks were fixated in $4 \%$ buffered formaldehyde solution. In each animal, five tissue blocks from one liver lobe were bisected to provide one sample for histology and one sample for SEM from each block. The samples for SEM were then dehydrated in a gradient series of alcohol and chemically dried with hexamethyldisilazane. Histological paraffin sections were stained with haematoxylin and eosin (H\&E). Histology and SEM were used to quantitatively evaluate the quality and distribution of the gelatine, the amount of fibrin, the integration of the 
Table 2. Randomisation of agents.

\begin{tabular}{|c|c|c|c|c|c|c|}
\hline \multirow[b]{2}{*}{ Wound } & \multicolumn{3}{|c|}{$\begin{array}{c}\text { Piglet } 1 \\
\text { (Physiological conditions) }\end{array}$} & \multicolumn{3}{|c|}{$\begin{array}{c}\text { Piglet } 2 \\
\text { (Hypotension, hypothermia and haemodilution) } \\
\end{array}$} \\
\hline & $\mathbf{L L}$ & ML & $\mathbf{R L}$ & $\mathbf{L L}$ & ML & $\mathbf{R L}$ \\
\hline 1 & Flosea ${ }^{\circledR}$ bT & Flosea ${ }^{\circledR}$ bT & Surgiflo $^{\circledR}$ bT & Surgiflo $^{\circledR}$ bT & Floseal ${ }^{\circledR} \mathrm{hT}$ & Floseal $^{\circledR} \mathrm{hT}$ \\
\hline 2 & Surgiflo $^{\circledR}$ bT & Surgiflo $^{\circledR}$ bT & Flosea ${ }^{\circledR} \mathrm{hT}$ & Flosea ${ }^{\circledR}$ bT & Flosea ${ }^{\circledR}$ bT & Surgiflo $^{\circledR}$ \\
\hline 3 & Floseal ${ }^{\circledR} \mathrm{hT}$ & Surgiflo $^{\circledR}$ & Surgiflo $^{\circledR}$ & Surgiflo $^{\circledR}$ & Surgiflo $^{\circledR}$ & Surgiflo ${ }^{\circledR}$ bT \\
\hline 4 & Surgiflo $^{\circledR}$ & Floseal ${ }^{\circledR} \mathrm{hT}$ & Floseal ${ }^{\circledR}$ bT & Floseal ${ }^{\circledR} \mathrm{hT}$ & Surgiflo $^{\circledR}$ bT & Floseal ${ }^{\circledR}$ bT \\
\hline 5 & Control & Control & Control & Control & Control & Control \\
\hline
\end{tabular}

LL: left liver lobe, ML: medial liver lobe, RL: right liver lobe, hT: 2500 IU human thrombin, bT: 5000 IU bovine thrombin.

gelatine into the fibrin network and the quantity of blood cells in the defect. The pathologists analysing the samples were blinded to both the agent used and the origin of the specimen.

\section{Results}

\subsection{Scanning Electron Microscopy Analysis of Agents before Application to the Wound}

The mean particle size of both agents ranged from 100 to $500 \mu \mathrm{m}$ (Figure 1). There were, however, important differences when comparing their geometrical and topographic characteristics; Floseal ${ }^{\circledR}$ particles were compact, flat and elongated with an irregular outline and Surgiflo ${ }^{\circledR}$ particles were spongy, more spherical in shape and were sometimes locally interconnected, creating a kind of network.

\subsection{In Vivo Analysis of the Ability of Surgiflo ${ }^{\circledR}$ and Floseal ${ }^{\circledR}$ to Control Haemostasis}

Wounds treated with Floseal ${ }^{\circledR}$ stopped bleeding after the first two minutes of compression in both animals; a lump of clotted gelatine was visible on top of the wound but the actual blood clot was not visible on the surface of the liver. In the piglet under normal physiological conditions, Surgiflo ${ }^{\circledR}$ produced a physiological blood clot in one out of three wounds; with the addition of thrombin, a degree of clotting was observed in all 3 wounds. In contrast, in the second piglet with hypotension, hypothermia and haemodilution, both Surgiflo ${ }^{(B}$ and Surgiflo $\left.{ }^{(}\right)$with thrombin each produced some degree of clotting in just one out of three applications. Rinsing away the surplus agent resulted in bleeding recommencing in the Surgiflo ${ }^{\circledR}$ and Surgiflo ${ }^{\circledR}$ with thrombin wounds that had clotted in the second animal (Figure 2). All control stab wounds continued bleeding after $2 \times 2$ minutes of compression and were either packed or sutured with $\operatorname{Vicryl}^{\circledR}$ (size 4/0) to prevent important blood loss. Table 3 gives an overview of the observations made after excess product was rinsed away.

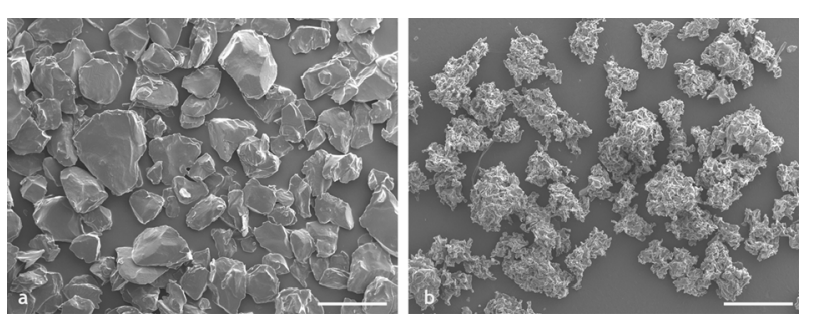

Figure 1. SEM of particles before application to the wound: a) Floseal ${ }^{\circledR}$; b) Surgiflo ${ }^{\circledR}($ bar $=500 \mu \mathrm{m})$.
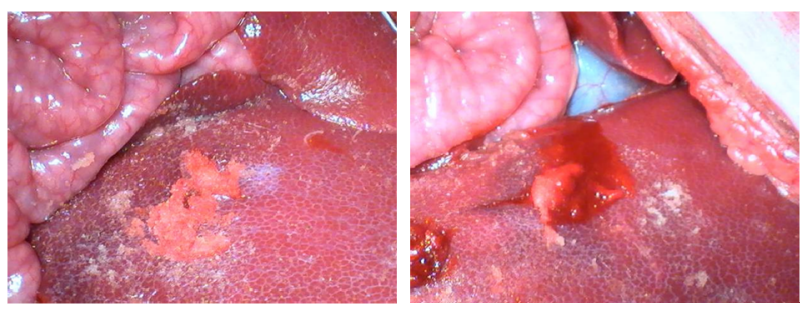

Figure 2. Perioperative view (piglet 2): left: immediate haemostasis with Floseal $^{\circledR}$; right: continued bleeding after application of Surgiflo ${ }^{\circledR}$.

\subsection{Microscopic Evaluation of the Wounds}

The H\&E stained microscopic samples showed clear differences between the two agents in terms of the size and structure of the gelatine, the presence of red blood cells and fibrin in the wound and in the adherence of the gelatine to the liver surface (Figure 3). The gelatine matrix created by Surgiflo ${ }^{\circledR}$ was more porous and surrounded by red blood cells. The particles were not strongly adherent to the liver surface and there was limited fibrin within the wound. In comparison, the dense gelatine particles in the Floseal ${ }^{\circledR}$ samples were closely adherent to the hepatocytes and the amount of fibrin in the Floseal ${ }^{\circledR}$ treated wounds was higher. There was no difference between the Floseal ${ }^{\circledR}$ samples prepared with $2500 \mathrm{IU}$ human thrombin or 5000 IU bovine thrombin. Adding thrombin to Surgiflo ${ }^{\circledR}$ did not appear to change the effectiveness of the agent in either piglet, as determined by microscopic evaluation. 
Table 3. Observations of haemostasis after excess product removed by rinsing.

\begin{tabular}{|c|c|c|c|c|c|c|}
\hline \multirow[t]{2}{*}{ Product } & \multicolumn{3}{|c|}{$\begin{array}{c}\text { Piglet } 1 \\
\text { (Physiological conditions) }\end{array}$} & \multicolumn{3}{|c|}{$\begin{array}{c}\text { Piglet } 2 \\
\text { (Hypotension, hypothermia and haemodilution) }\end{array}$} \\
\hline & LL & ML & $R L$ & LL & ML & RL \\
\hline Flosea $\mathrm{l}^{\circledR} \mathrm{hT}$ & + & + & + & + & + & + \\
\hline Flosea $\mathrm{l}^{\circledR} \mathrm{bT}$ & + & + & + & + & + & + \\
\hline Surgiflo $^{\circledR}$ & \pm & - & - & - & $-/ \pm$ & - \\
\hline Surgiflo ${ }^{\circledR} \mathrm{bT}$ & \pm & $-/ \pm$ & \pm & - & $-/ \pm$ & - \\
\hline Control & - & - & - & - & - & - \\
\hline
\end{tabular}

hT: 2500 IU human thrombin, bT: 5000 IU bovine thrombin, LL: left lobe, ML: medial lobe, RL: right lobe, -: no haemostasis, \pm : some haemostasis, blood leaking, +: good haemostasis, dry.
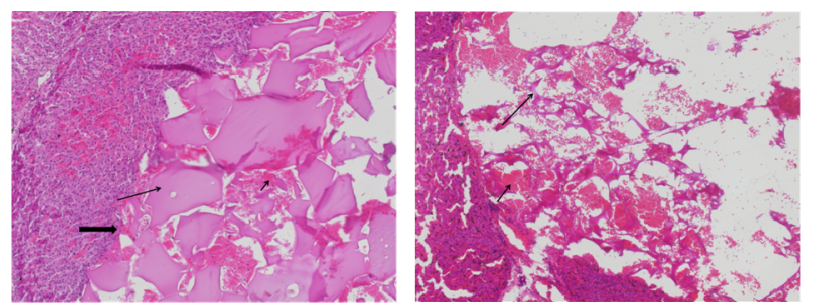

Figure 3. H\&E stain (piglet 2): left: Transition of the liver to the Floseal ${ }^{\circledR}$ (bovine thrombin) filled defect: large gelatine particles (long arrow) are well attached to the defect margin. The interspace between the particles is filled with a few red blood cells (short arrow) and fibrin material (block arrow); right: Defect margin of the wound filled with Surgiflo $^{\circledR}$ (bovine thrombin) shows the dominance of the blood cells (short arrow) over the cross section area of the gelatine particles (long arrow), there is very little fibrin present (HES, original magnification $100 \times$ ).

The SEM findings were similar to those obtained with the light microscope. There was a clear demonstration of the adhesion of the gelatine in Floseal ${ }^{\circledR}$ to the liver surface and the formation of a dense fibrin network around the particles. The network became continuously looser towards the middle of the defect, where the gelatine particles were lying almost free in the cavity of the wound. The spongy particles in Surgiflo ${ }^{\circledR}$ did not prevent further bleeding, resulting in a larger amount of red blood cells and less production of fibrin within the wound. In wounds treated with Floseal ${ }^{\circledR}$, gelatine was present all the way down to the base of the defect, but the gelatine in Surgiflo ${ }^{\circledR}$ appeared to be pushed out towards the liver surface by the blood emerging from the wound (Figure 4). The results with Floseal ${ }^{\circledR}$ were comparable between piglets, whereas with Surgiflo ${ }^{\circledR}$ there was increased loss of the agent from the wounds after washing in the second piglet with hypotension, hypothermia and haemodilution compared with the first piglet (physiological conditions).

\section{Discussion}

Whereas the qualitative observations of the haemostasis

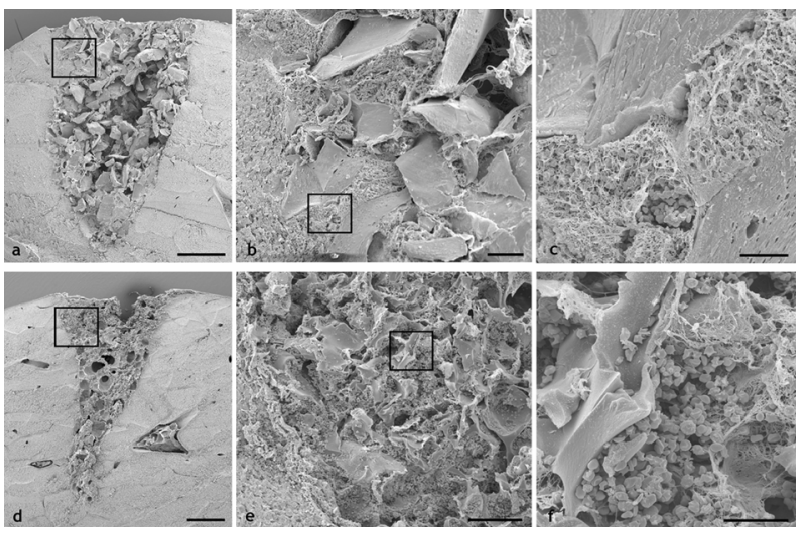

Figure 4. Scanning electron microscope (piglet 1): a-b-c: Floseal ${ }^{\circledR}$ bovine thrombin: a) The overview image shows the complete filling of the wound down to the bottom of the defect. b) Magnification of the area indicated in a) shows the continuous transition of the liver tissue and the defect-filling material. The dense particles adhere well to the defect margin of the liver and are surrounded by a dense fibrin network. c) Magnification of the area indicated in b) shows the tight adhesion of the dense fibrin network to the gelatine particles. d-e-f: Surgiflo ${ }^{\circledR}$ bovine thrombin: d) Overview image of the Surgiflo ${ }^{\circledR}$-filled defect with large holes in the filling material. e) Magnification of the area indicated in d) shows the spongy morphology of the particles and a distinct margin of the liver defect. f) A magnification of the indicated area in image e) visualises the surrounding of the irregular particles which mainly consist of blood cells and short fibrin fibrils. $(a \& d$ : bar $=1 \mathrm{~mm}$, b\&e: bar $=100 \mu \mathrm{m}, c \& f:$ bar $=20 \mu \mathrm{m})$.

obtained with Floseal ${ }^{\circledR}$ and Surgiflo ${ }^{\circledR}$ could be influenced by user or observer bias as observers were not blinded to the characteristic picture of the agent while being applied, the histological and SEM findings, as interpreted by a pathologist blinded to the agent applied, showed a clear difference between the two products.

In Floseal ${ }^{\circledR}$-filled incisions, a strongly adherent gelatine-fibrin agglomerate was found from the defect margins down to the bottom of the lesion. The centre of the clot was almost blood-free and gelatine particles were 
lying more or less freely. This suggests an immediate initiation of blood coagulation occurring directly at the site where the blood was leaking into the wound. SEM imaging demonstrated that the large gelatine particles of Floseal ${ }^{B}$ were held against the wound surface by fibrin strands, which were effectively created through fibrinogen activation by the thrombin present in the agent. The activity of the agent did not appear to be influenced by whether the added thrombin was of human or bovine origin and whether the dose was $2500 \mathrm{IU}$ or $5000 \mathrm{IU}$. The flat surfaces of the Floseal ${ }^{\circledR}$ particles covered the wound surface and were kept in place by the rapidly formed fibrin. These mechanisms are likely to sustain the clotting process, resulting in effective haemostasis.

With Surgiflo ${ }^{\circledR}$, the particles were less well integrated into the fibrin and were mainly found at the top of the wound. Furthermore, the inner region of the wound was mainly filled with erythrocytes with only a sparse fibrin network present, suggesting less effective haemostasis. The Surgiflo ${ }^{\circledR}$ particles did not seem to activate clotting rapidly, hence allowing the wound to continue bleeding. This blood appeared to push the gelatine particles up and out of the wound, allowing them to wash away. The spongy morphology of Surgiflo ${ }^{\circledR}$ may have caused air to be trapped inside the particles, resulting in a less effective covering of the wound surface that failed to initiate clotting, and causing the gelatine to float on the surface of the upwelling blood. Similar observations were made during sample processing, where Surgiflo ${ }^{\circledR}$ particles floated on the top of the solution, whereas Floseal ${ }^{\circledR}$ particles sank immediately.

In the animal with hypotension, hypothermia and haemodilution, requiring inotropic support), Floseal ${ }^{\circledR}$ was as effective under normal physiological conditions, providing effective haemostasis in all three wounds. In contrast, Surgiflo ${ }^{\circledR}$ was completely washed out of the wound, and only a minor degree of clotting was observed in one wound after two rounds of compression.

These results have implications for clinical practice as effective haemostasis is linked to improved surgical outcomes. Absorbable topical haemostatic agents provide a viable alternative where conventional methods are ineffective or impractical. However their benefits must be carefully considered against potential adverse effects. Although rare, these include anaemia, atrial fibrillation, infection, rash, hypotension, respiratory distress, confusion, arrhythmias, arterial thrombosis, and fever [7]. In addition, expansion of a topical haemostatic agent within the treated region can result in complications such as pressing nerves in surrounding tissue against bone or hard tissue [8]. Surgeons should consider the maximum swell volume of the product used and its potential effect on surrounding areas. Despite these considerations, topical agents remain a powerful tool to achieve haemostasis during surgical procedures.
There are some limitations to this study. Firstly, this is a qualitative study in 2 piglets consisting of 6 lesions per group and 12 lesions per type of gelatine material, and no quantitative techniques or statistical assessments were undertaken. In addition, this study only considers one measure of haemostasis - the presence or absence of clotting - and does not incorporate any other aspects of the clinical evaluation of haemostasis, such as the assessment of disease symptoms and response to treatment. The amount of blood lost from the wounds was not measured, and therefore the clinical significance of this blood loss, both from treated and control wounds, is uncertain. It is also unclear whether each stab wound on each liver lobe caused similar degrees of blood loss and whether the damage to these sites affected other wound sites, for example by reducing blood flow. Finally, basic coagulation tests were not undertaken in either animal, making it difficult to speculate why Surgiflo ${ }^{\circledR}$ was not effective in the animal with hypotension, hypothermia and haemoidilution. Despite these limitations, differences between the two scenarios could be clearly observed.

\section{Conclusion}

With regard to the results of this qualitative experiment, Floseal ${ }^{\mathbb{B}}$ was able to create a dense and stable blood clot, even in a piglet with hypotension, hypothermia and haemodilution. Floseal ${ }^{\circledR}$ may therefore offer some benefits compared with Surgiflo ${ }^{\circledR}$, which in this experiment resulted in comparatively reduced clotting, particularly when haemostasis was impaired. Further experiments in animals and humans would be needed before one product could be recommended over the other for specific clinical situations and applications.

\section{Acknowledgements}

The test animals, theatre time and products used, were provided by the Ludwig Boltzmann Institute. The University Hospital of Brussels and the Medical University of Vienna provided the logistics for the microscopical studies. The Cell Imaging and Ultrastructure Research Unit at the University of Vienna provided the equipment for the electron microscopic investigations.

Medical writing assistance in editing the manuscript was provided by Fishawack Communications Ltd and funding for their support was provided by Baxter Biosurgery Inc.

\subsection{Competing Interests}

The authors of this article wish to state the following conflict of interest with products discussed in this article: Dr Coenye and Prof. van Griensven have received fees from Baxter Bioscience Inc. for consultancy, not in relation to the experiment discussed in this article; Dr Bour- 
gain, Dr Keibl and Mrs Nürnberger report no potential conflicts of interest.

\subsection{Authors' Contributions}

KEC initiated and conducted the experiment. CK and $\mathrm{MvG}$ participated in the design of the study. CK was also responsible for the animals before and during the observations. CB conducted the light microscopy examinations of the samples. SN conducted the scanning electron microscope study.

\subsection{Authors' Information}

This study was purely investigator-driven and resulted from the absence of any comparison between the agents observed and clinically observed differences between the products.

\section{REFERENCES}

[1] H. Seyednejad, M. Imani, T. Jamieson and A. M. Seifalian, "Topical Haemostatic Agents," British Journal of Surgery, Vol. 95, No. 10, 2008, pp. 1197-1225. doi: $10.1002 /$ bjs. 6357

[2] G. J. Murphy, B. C. Reeves, C. A. Rogers, S. I. Rizvi, L. Culliford and G. D. Angelini, "Increased Mortality, Postoperative Morbidity, and Cost After Red Blood Cell Transfusion in Patients Having Cardiac Surgery," Circu- lation, Vol. 116, No. 22, 2007, pp. 2544-2552. doi:10.1161/CIRCULATIONAHA.107.698977

[3] A. Shander, "Financial and Clinical Outcomes Associated with Surgical Bleeding Complications," Surgery, Vol. 142, Suppl. 4, 2007, pp. S20-S25. doi:10.1016/j.surg.2007.06.025

[4] M. Leixnering, J. Reichetseder, A. Schultz, M. Figl, E. Wassermann, H. Thurnher and H. Redl, "Gelatine Thrombin Granules For Hemostasis in a Severe Traumatic Liver and Spleen Rupture Model in Swine," Journal of Trauma-Injury Infection \& Critical Care, Vol. 64, No. 2, 2008, pp. 456-461. doi:10.1097/TA.0b013e3180340de1

[5] M. C. Oz, D. M. Cosgrove, B. R. Badduke, J. D. Hill, M. R. Flannery, R. Palumbo and N. Topic, "Controlled Clinical Trial of a Novel Hemostatic Agent in Cardiac Surgery. The Fusion Matrix Study Group," The Annals of Thoracic Surgery, Vol. 69, No. 5, 2000, pp. 1376-1382. doi:10.1016/S0003-4975(00)01194-2

[6] R. A. De la Torre, S. L. Bachman, A. A. Wheeler, K. N. Bartow and J. S. Scott, "Hemostasis and Hemostatic Agents in Minimally Invasive Surgery," Surgery, Vol. 142, No. 4, 2007, pp. S39-S45. doi:10.1016/j.surg.2007.06.023

[7] Baxter Healthcare SA, "Floseal Instructions for Use," Zurich.

[8] S. Samadrula, "Topical Hemostatic Agents in Surgery: A Surgeon's Perspective," AORN Journal, Vol. 88, No. 3, 2008, pp. S2-S11. doi:10.1016/S0001-2092(08)00586-3 